Original article

\title{
Exposure to cytotoxic drugs threatens the health of staff in oncology wards
}

\author{
Mohsen Momeni ${ }^{1}$, Mehrdad Askarian ${ }^{2}$, Hossein Azad ${ }^{1}$, Mina Danaei ${ }^{1}$ \\ ${ }^{1}$ Kerman University of Medical Sciences, Kerman, Iran \\ ${ }^{2}$ Shiraz University of Medical Sciences, Shiraz, Iran
}

Received 10 May 2020, Revised 9 May 2021, Accepted 26 July 2021

(C) 2020, Russian Open Medical Journal

\begin{abstract}
Background - Cancer is one of the leading causes of death worldwide. Using cytotoxic drugs for cancer treatment is increased. The hazardous effects of occupational exposure to cytotoxic drugs are challenging.

Objective - This study aimed to compare the frequency of adverse effects and using personal protective equipment (PPE) between the staff of oncology wards and other hospital wards staff in Iran.

Methods - A cross-sectional study with a control group was conducted on female staff members in educational hospitals, selected through convenience sampling. A data collection form was designed for this study. It includes demographic data, acute complications (allergic and neurologic reactions), chronic complications (infertility, menstrual disorders, malignancy, and congenital malformations), and use of PPE. Data analysis was performed using SPSS software through Chi-square and Mann-Whitney tests.

Results - The frequencies of chronic complications were not statistically different between the two groups. The frequency of itching $(P=0.001)$, hair loss $(P=0.003)$, itchy eyes $(P=0.001)$, watery eyes $(P=0.001)$, runny nose $(P=0.003)$, headache $(P=0.001)$, vertigo $(P=0.007)$, and nausea $(P=0.008)$ were significantly higher in oncology wards nurses. Among different $P P E$, only the frequency of using the mask $(P=$ $0.001)$, and glasses $(P=0.027)$ were significantly higher in the staff of oncology wards.

Conclusion - Despite the frequency of acute complications of exposure to cytotoxic drugs, oncology staff does not fully adhere to the standard precautions. Providing effective training and emphasis on implementing accreditation laws can improve the existing situation.
\end{abstract}

Keywords: occupational exposure, nurses, chemotherapy, neoplasms, personal protective equipment.

Cite as Momeni M, Askarian M, Azad H, Danaei M. Exposure to cytotoxic drugs threatens the health of staff in oncology wards. Russian Open Medical Journal 2021; 10: e0316.

Correspondence to Mina Danaei. Phone: +98- 913-3409727. Fax: +98-343-31325407. Email: m.danaei@kmu.ac.ir.

\section{Introduction}

Nowadays, considering the advances in health science, somecancers are diagnosed at an earlier stage, and patients receive multiple chemotherapy agents for an extended length of time [1]. Cytotoxic drugs are therapeutic agents that affect cancerous and non-cancerous cells simultaneously. due to the teratogenic, mutagenic and carcinogenic effects of cytotoxic drugs, long-term exposure to them in the workplace is associated with adverse outcomes [2]. According to the International Agency for Research on Cancer (IARC), ten cytotoxic drugs are classified as carcinogenic agents for humans (Group 1), and ten cytotoxic drugs are classified as probable carcinogenic agents for humans (Group 2A) [3].

The frequency of adverse effects of occupational exposure to cytotoxic drugs varies between different staff members depending the duration and frequency of exposure to cytotoxic drugs, the toxicity of different drugs, and the vulnerability of each staff member [4-6]. Nurses who work in wards where cytotoxic drugs are used are at risk for the adverse effects of these drugs, including headache, nausea, vomiting, abdominal pain, skin irritation and dermatitis, hair loss, blood count decline, damage in peripheral lymphocytes, liver damage, reproductive disorders, congenital abnormalities, fetal loss, miscarriage, sub-fertility, low birth weight, and breast and rectal cancer [1, 6-9].

Most exposure to cytotoxic drugs in nurses is through inhalation and skin absorption [10]. On the other hand, several studies have demonstrated that work surfaces are contaminated with cytotoxic drugs even after they are cleaned [3]. Protecting health care workers from the adverse effects of cytotoxic drugs is challenging. International and national guidelines are provided to minimize the adverse occupational effects of cytotoxic drugs, but adherence to these guidelines is insufficient in developing countries, including Iran $[9,11,12]$.

Some studies have demonstrated different signs and symptoms of adverse effects of cytotoxic drugs among nurses [13, 14]. Due to the importance of occupational safety, this study was conducted in Kerman, Iran, comparing the frequency of adverse effects of cytotoxic drugs among the oncology staff and staff who worked in other hospital wards. We also asked the staff about their safety behaviors.

\section{Material and Methods}

This cross-sectional study with a control group was conducted in Kerman, Iran, in 2019. All 37 female staff members, who worked 
in the oncology wards of different public hospitals, including Afzalipour Hospital, Shahid Bahonar Hospital, and Javadolaemeh Clinic, were recruited for the study. Among other different wards of Afzalipour and Shahid Bahonar hospitals, 42 female staff members were selected as the control group using the convenience sampling method. Staff members with a history of chronic or mental disorders, those with a history of cytotoxic drug consumption, and staff who did not give consent to take part in the survey were excluded from the study. Also, staff with a history of working in the oncology wards were excluded from the control group. Due to the low number of male nurses, only female staff were included in the study.

After obtaining the ethical code (IR.KMU.AH.REC.1397.2742) from the Ethics Committee of Kerman University of Medical Sciences, the data collection process began. The data collecting form included the socio-demographic characteristics of staff (gender, marital status, educational level, work experience, type of employment, duration of working in the ward under study, income satisfaction, and job satisfaction), information about the skin disorders (itching, skin lesions, and hair loss), allergic reactions (itchy eyes, watery eyes, runny nose, sneezing, and chronic cough), neurologic reactions (headache, dizziness, nausea, and vomiting), and reproductive disorders (spontaneous abortion, stillbirth, congenital anomalies, infertility, low birth weight, irregular menstrual cycles, and abnormal uterine bleeding). Income satisfaction and job satisfaction were assessed with a 5-point Likert scale ranging from very low to very high. The survey also asked about the frequency of utilization of personal protective equipment (PPE), including gloves, gown, glasses, and masks by nurses.

The data were entered into the IBM SPSS software (version 20). The chi-square test, Fisher- exact test and the Mann-Whitney $\mathrm{U}$ test were used for analysis. The significance level was set at less than 0.05

Table 1. Comparison of demographic variables between two groups of participants

\begin{tabular}{|c|c|c|c|c|c|}
\hline \multirow{2}{*}{ Demographic Variable } & \multicolumn{2}{|c|}{ Oncology wards } & \multicolumn{2}{|c|}{ Other wards } & \multirow{2}{*}{ P-value } \\
\hline & Median & IQR & Median & IQR & \\
\hline Age (year) & 28 & 11 & 28 & 10 & 0.755 \\
\hline work experience (year) & 5 & 8 & 4.5 & 8 & 0.985 \\
\hline \multirow{2}{*}{$\begin{array}{l}\text { work experience in } \\
\text { current ward (year) }\end{array}$} & 2 & 7.5 & 2 & 2 & 0.297 \\
\hline & Frequency & Percent & Frequency & Percent & \\
\hline \multicolumn{6}{|l|}{ Educational status } \\
\hline$\leq 16$ years & 5 & 14.3 & 2 & 3.9 & 0.086 \\
\hline$>17$ Years & 30 & 85.7 & 49 & 96.1 & \\
\hline \multicolumn{6}{|l|}{ Marital status } \\
\hline Married & 26 & 74.3 & 32 & 37.3 & 0.262 \\
\hline Unmarried & 9 & 25.7 & 19 & 62.7 & \\
\hline \multicolumn{6}{|l|}{ Job } \\
\hline Nurse & 31 & 88.6 & 37 & 72.5 & 0.073 \\
\hline Others & 4 & 11.4 & 14 & 27.5 & \\
\hline \multicolumn{6}{|l|}{ Employment status } \\
\hline Recruitment & 16 & 47.1 & 28 & 54.9 & 0.478 \\
\hline Un recruitment & 18 & 52.9 & 23 & 45.1 & \\
\hline \multicolumn{6}{|l|}{ Job satisfaction } \\
\hline Yes & 16 & 45.7 & 22 & 44.9 & 0.941 \\
\hline No & 19 & 54.3 & 27 & 55.1 & \\
\hline \multicolumn{6}{|l|}{ Income satisfaction } \\
\hline Yes & 7 & 20 & 11 & 22.4 & 0.787 \\
\hline No & 28 & 80 & 38 & 77.6 & \\
\hline
\end{tabular}

Table 2. Comparison frequency of acute side effects between two groups of participants

\begin{tabular}{|c|c|c|c|c|c|}
\hline \multirow{2}{*}{ Acute Side effects } & \multicolumn{2}{|c|}{ Oncology wards } & \multicolumn{2}{|c|}{ Other wards } & \multirow{2}{*}{$P$-value } \\
\hline & Frequency (\%) & Percent & Frequency (\%) & Percent & \\
\hline \multicolumn{6}{|c|}{ 年 } \\
\hline Yes & 27 & 73 & 20 & 38.5 & 0.001 \\
\hline No & 10 & 27 & 32 & 61.5 & \\
\hline \multicolumn{6}{|l|}{ Skin lesions } \\
\hline Yes & 18 & 48.6 & 16 & 30.8 & 0.087 \\
\hline No & 19 & 51.4 & 36 & 69.2 & \\
\hline \multicolumn{6}{|l|}{ Hair loss } \\
\hline Yes & 17 & 45.9 & 9 & 17.3 & 0.003 \\
\hline No & 20 & 54.1 & 43 & 82.7 & \\
\hline \multicolumn{6}{|l|}{ Eyes itching } \\
\hline Yes & 20 & 54.1 & 9 & 17.3 & 0.001 \\
\hline No & 17 & 45.9 & 43 & 82.7 & \\
\hline \multicolumn{6}{|l|}{ Tearing } \\
\hline Yes & 20 & 54.1 & 8 & 15.4 & 0.001 \\
\hline No & 17 & 45.9 & 44 & 84.6 & \\
\hline \multicolumn{6}{|l|}{ Nose discharge } \\
\hline Yes & 19 & 51.4 & 11 & 21.2 & 0.003 \\
\hline No & 18 & 48.6 & 41 & 78.8 & \\
\hline \multicolumn{6}{|c|}{ Chronic Sneezing and coughing } \\
\hline Yes & 13 & 35.1 & 11 & 21.2 & 0.143 \\
\hline No & 24 & 64.9 & 41 & 78.8 & \\
\hline \multicolumn{6}{|l|}{ Headache } \\
\hline Yes & 25 & 67.6 & 14 & 26.9 & 0.001 \\
\hline No & 12 & 32.4 & 38 & 73.1 & \\
\hline \multicolumn{6}{|l|}{ Vertigo } \\
\hline Yes & 13 & 35.1 & 6 & 11.5 & 0.007 \\
\hline No & 24 & 64.9 & 46 & 88.5 & \\
\hline \multicolumn{6}{|l|}{ Nausea } \\
\hline Yes & 14 & 37.8 & 7 & 13.5 & 0.008 \\
\hline No & 23 & 62.2 & 45 & 86.5 & \\
\hline \multicolumn{6}{|l|}{ Vomiting } \\
\hline Yes & 7 & 18.9 & 5 & 9.6 & 0.225 \\
\hline No & 30 & 81.1 & 47 & 90.4 & \\
\hline
\end{tabular}

\section{Results}

In this study, 89 staff members were studied in two oncology wards $(n=37)$ and other wards $(n=52)$. There was no significant difference between the two groups in the median of age $(P=0.755)$, work experience $(P=0.985)$, and work experience in the current ward $(\mathrm{P}=0.297)$ (Table 1$)$. The results also showed that demographic variables and other probable confounders, including educational status, marital status, job income satisfaction, job satisfaction, and employment status, were not significantly different between the two groups (Table 1).

The comparison of the acute side effects between the two groups is presented in Table 2 . The results showed that $73 \%$ of the oncology staff and $38.5 \%$ of the staff in the other sections had skin itching, with a significant difference $(P=0.001)$. Also, $45.9 \%$ of oncology staff and $17.3 \%$ of staff in other wards had hair loss, which was significant $(P=0.003)$. Nearly $54.1 \%$ of oncology staff and $17.3 \%$ of staff in other wards had eye itching, which was significant $(P=0.001)$. Approximately $54.1 \%$ of oncology staff and $15.4 \%$ of staff in other wards reported experiencing tearing $(P=0.001)$. Nose discharge was reported by $51.4 \%$ of oncology staff and $21.2 \%$ in staff of other wards $(P=0.003)$. Nearly $67.6 \%$ of the oncology staff and $26.9 \%$ of the other staff members reported having headaches, which showed a significant difference $(P=0.001)$. The frequency of dizziness reported was $35.1 \%$ in oncology staff and $11.5 \%$ in staff in other wards, which was statistically significant $(\mathrm{P}=0.007)$. Approximately $37.8 \%$ of oncology 
staff and $13.5 \%$ of staff in other wards reported having nausea which was statistically significant $(P=0.001)$.

Comparison of frequency of pregnancy-related chronic fetal and neonatal side effects, menstrual disorders, and malignancy in the two groups showed no significant difference between the two groups. However, except for infertility, other side effects were higher in oncology staff than in other wards (Table 3).

The results showed that gloves and masks were the most common protective equipment used by all participants. Nearly $89.2 \%$ of the oncology staff and $42.3 \%$ of staff in other wards used the mask, which showed a statistically significant difference $(P=0.001)$. Nearly $40.5 \%$ of oncology staff and $19.2 \%$ of the staff in other wards wore glasses which showed a statistically significant difference $(P=0.027)$. The results showed no significant difference between the frequency of use of gowns and gloves in the two groups (Table 4).

Table 3. Comparison frequency of chronic gynecologic, obstetric side effects between two groups of participants

\begin{tabular}{|c|c|c|c|c|c|}
\hline \multirow{2}{*}{ Chronic Side effects } & \multicolumn{2}{|c|}{ Oncology wards } & \multicolumn{2}{|c|}{ Other wards } & \multirow{2}{*}{ P-value } \\
\hline & Frequency (\%) & Percent & Frequency (\%) & Percent & \\
\hline \multicolumn{6}{|l|}{ Abortion } \\
\hline Yes & 6 & 23.1 & 3 & 9.4 & 0.274 \\
\hline No & 20 & 76.9 & 29 & 90.6 & \\
\hline \multicolumn{6}{|l|}{ Stillbirth } \\
\hline Yes & 1 & 3.8 & 1 & 3.1 & 0.881 \\
\hline No & 25 & 96.2 & 31 & 96.9 & \\
\hline \multicolumn{6}{|c|}{ Congenital malformation } \\
\hline Yes & 1 & 3.8 & 1 & 3.1 & 0.881 \\
\hline No & 25 & 96.2 & 31 & 96.9 & \\
\hline \multicolumn{6}{|l|}{ Infertility } \\
\hline Yes & 1 & 3.8 & 3 & 9.4 & 0.620 \\
\hline No & 25 & 96.2 & 29 & 90.6 & \\
\hline \multicolumn{6}{|l|}{ Low birth weight } \\
\hline Yes & 7 & 26.9 & 7 & 21.9 & 0.655 \\
\hline No & 19 & 73.1 & 25 & 78.1 & \\
\hline \multicolumn{6}{|l|}{ Malignancy } \\
\hline Yes & 1 & 2.7 & 0 & 0 & 0.416 \\
\hline No & 36 & 97.3 & 52 & 100 & \\
\hline \multicolumn{6}{|c|}{ Oligomenorrhea /Polymenorrhea } \\
\hline Yes & 19 & 51.4 & 20 & 38.5 & 0.227 \\
\hline No & 18 & 48.6 & 32 & 61.5 & \\
\hline \multicolumn{6}{|c|}{ Hypermenorrhea /Hypo menorrhea } \\
\hline Yes & 17 & 45.9 & 18 & 34.6 & 0.281 \\
\hline No & 20 & 54.1 & 34 & 65.4 & \\
\hline
\end{tabular}

Table 4. Comparison frequency of PPE use between two groups of participants

\begin{tabular}{|c|c|c|c|c|c|}
\hline \multirow{2}{*}{$\begin{array}{c}\text { Personal protective } \\
\text { equipment }\end{array}$} & \multicolumn{2}{|c|}{ Oncology wards } & \multicolumn{2}{|c|}{ Other wards } & \multirow{2}{*}{ P-value } \\
\hline & Frequency (\%) & Percent & Frequency (\%) & Percent & \\
\hline \multicolumn{6}{|c|}{ Gown } \\
\hline Yes & 14 & 37.8 & 12 & 23.1 & 0.131 \\
\hline No & 23 & 62.2 & 40 & 76.9 & \\
\hline \multicolumn{6}{|l|}{ Mask } \\
\hline Yes & 33 & 89.2 & 22 & 42.3 & 0.001 \\
\hline No & 4 & 10.8 & 30 & 57.7 & \\
\hline \multicolumn{6}{|l|}{ Glasses } \\
\hline Yes & 15 & 40.5 & 10 & 19.2 & 0.027 \\
\hline No & 22 & 59.5 & 42 & 80.8 & \\
\hline \multicolumn{6}{|l|}{ Gloves } \\
\hline Yes & 35 & 94.6 & 46 & 88.5 & 0.319 \\
\hline No & 2 & 5.4 & 6 & 11.5 & \\
\hline
\end{tabular}

\section{Discussion}

To consider the confounding factors, the present study, assessed the frequency of demographic factors, job and income satisfaction, and socioeconomic factors in the two study groups, revealing no significant difference between them. Comparing the frequency of acute side effects showed that the frequency of skin and allergic reactions (except for sneezing and chronic cough) and neurological reactions (except for vomiting) were significantly higher in oncology personnel than in others. Worthington (2000) showed that nurses who had been exposed to cytotoxic drugs for a long time without adequate protection experienced several side effects such as dizziness, headache, hair loss, allergic reactions, nausea, respiratory disorders, liver fibrosis, bladder cancer, leukemia, and reproductive system damage [15]. Also, other studies reported the experience of different acute side effects by nurses who worked in oncology wards, including headache, nausea, vomiting, abdominal pain, dermatitis, allergic symptoms, and hair loss $[6-9,13,16]$. Lack of a control group is a limitation of some cross-sectional studies on occupational exposure to cytotoxic drugs. The use of a control group and adjusting confounders in the present study enabled us to compare the frequency of acute side effects in oncology ward personnel with personnel of other wards. Considering these occupational hazards, the occupational health system of hospitals should monitor and evaluate the personnel of chemotherapy wards with more precision.

Comparing the frequency of chronic side effects between the two groups showed that none of these chronic side effects was significantly different between the two groups. However, except for infertility, other cases were more common in oncology staff than in other staff. Several studies have shown that occupational exposure to cytotoxic drugs has genotoxic effects, and is able to change genetic biomarkers [17-19]. The results of a systematic review showed an association between occupational exposure to cytotoxic drugs and spontaneous abortion [4]. Also, one review study showed that occupational exposure to cytotoxic drugs is associated with an increased risk of miscarriage, congenital malformations, and infertility [7]. The results of a cohort study showed an increased incidence of breast and rectal cancer in women with occupational exposure to cytotoxic drugs [20]. In this study, most of the chronic side effects were more common in oncology staff, but there was no significant difference. Some confounding factors, including the history of polycystic ovary syndrome and other factors affecting the menstrual process, could affect the significance of the results.

On the other hand, the average experience in the oncology ward in the study subjects was two years. Therefore, one reason for the insignificant difference in the frequency of these side effects betweeb the two groups was probably the relatively short exposure to cytotoxic drugs. In this study, a significant number of personnel were single, so they were not included in analyzing data on the frequency of side effects associated with neonatal and fetal malformations. During analysis, the low sample size can reduce the difference in the frequency of side effects between the two groups. Despite the differences in results, most studies emphasize the carcinogenic, teratogenic, and mutagenic effects of cytotoxic drugs. Therefore, it is vital for oncology ward health care workers to follow standard precautions.

The use of PPE by personnel was compared in the two study groups, which showed that oncology personnel were significantly 
more likely to use masks and glasses than other personnel. The frequency of use of gowns and gloves were not significantly different between the two groups. Different principles and guidelines were developed to protect occupational contact with cytotoxic drugs by the Australian Oncology Society, the American Hospital Pharmacologists, and the American Oncology Nurses Association [21]. In the present study, among the oncology personnel, $37.8 \%$ used gowns, $89.2 \%$ used masks, $40.5 \%$ used glasses, and $94.6 \%$ used gloves. There were significant differences between oncology ward nurses and other nurses in relation to wearing a masks and glasses. Evaluating the oncology nurses at Shiraz University of Medical Sciences (2013) showed that the frequency of using gowns, masks, glasses, and gloves were $73 \%$, $90 \%, 71 \%$, and $95 \%$, respectively (12). Evaluating the outpatient and office-based oncology nurses in the United States (2003) showed that nearly $94 \%$ of nurses usually wore gloves, but less than $6 \%$ of them usually used respiratory and face protection equipment [22]. One study among chemotherapy ward nurses in Isfahan, Iran, reported the frequency of using gowns, masks, glasses, and gloves as $58.9 \%, 79.5 \%, 58.9 \%$, and $100 \%$, respectively [23]. Comparing the frequency of using PPE in different oncology settings in Iran demonstrated that PPE compliance is not acceptable among Kerman hospital oncology ward nurses. Also, other nurses in Kerman hospitals did not comply with PPE use standards. Policy-makers should promote nurses' knowledge of and attitude to PPE use. Implementing and evaluating the efficacy of precaution regulations in hospitals is essential to protect personnel from occupational hazards.

One of the strengths of the present study is using a control group to evaluate the side effects of chemotherapy in oncology staff. However, the cross-sectional nature of this study, the need for prolonged exposure time for the occurrence of chronic side effects, lack of control over all confounding factors, and the small sample size were the limitations of this study. Future longitudinal studies with a larger sample size and follow-up period are recommended to investigate the long-term effects of exposure to chemotherapy drugs.

\section{Acknowledgments}

The Authors thanks all participants of this study for their kind cooperation. The present article is based on the thesis by Hossein Azad and was financially supported by Kerman University of Medical Sciences (Grant No. 96000691)

\section{Conflict of interest}

None declared

\section{References}

1. Keat $\mathrm{CH}$, Sooaid NS, Yun CY, Sriraman M. Improving Safety-Related Knowledge, Attitude and Practices of Nurses Handling Cytotoxic Anticancer Drug: PharmacistsExperience in a General Hospital, Malaysia. Asian Pac J Cancer Prev 2013; 14(1): 69-73. https://doi.org/10.7314/apjcp.2013.14.1.69.

2. Ramazani M, Jaktaji RP, Shirazi FH, Tavakoli-Ardakan M, Salimi A, Pourahmad J. Analysis of apoptosis related genes in nurses exposed to anti-neoplastic drugs. BMC Pharmacol Toxicol 2019; 20(1): 74. https://doi.org/10.1186/s40360-019-0372-0.

3. Sottani $\mathrm{C}$, Porro $\mathrm{B}$, Imbriani $\mathrm{M}$, Minoia $\mathrm{C}$. Occupational exposure to antineoplastic drugs in four Italian health care settings. Toxicol Lett 2012; 213(1): 107-115. https://doi.org/10.1016/j.toxlet.2011.03.028.
4. Dranitsaris G, Johnston M, Poirier S, Schueller T, Milliken D, Green E, et al. Are health care providers who work with cancer drugs at an increased risk for toxic events? A systematic review and meta-analysis of the literature. J Oncol Pharm Pract 2005; 11(2): 69-78. https://doi.org/10.1191/1078155205jp155oa.

5. Shahrasbi AA, Afshar M, Shokraneh F Monji F Noroozi M EbrahimiKhojin $M$, et al. Risks to health professionals from hazardous drugs in Iran: a pilot study of understanding of healthcare team to occupational exposure to cytotoxics. EXCLI J 2014; 13: 491-501. https://pubmed.ncbi.nlm.nih.gov/26417276.

6. Connor TH, McDiarmid MA. Preventing occupational exposures to antineoplastic drugs in health care settings. CA Cancer J Clin 2006; 56(6): 354-365. https://doi.org/10.3322/canjclin.56.6.354.

7. Connor TH, Lawson CC, Polovich M, McDiarmid MA. Reproductive health risks associated with occupational exposures to antineoplastic drugs in health care settings: a review of the evidence $J$ Occup Environ Med 2014; 56(9): 901-910. https://doi.org/10.1097/jom.0000000000000249.

8. Lawson CC, Rocheleau CM, Whelan EA, Lividoti Hibert EN, Grajewski B, Spiegelman D, et al. Occupational exposures among nurses and risk of spontaneous abortion. Am J Obstet Gynecol 2012; 206(4): 327.e1-8. https://doi.org/10.1016/i.ajog.2011.12.030.

9. Askarian M, Momeni M, Danaei M. The management of cytotoxic drug wastes in Shiraz, Iran: an overview of all government and private chemotherapy settings, and comparison with national and international guidelines. Waste Manag Res 2013; 31(6): 541-548. https://doi.org/10.1177/0734242x13476747.

10. Kyprianou M, Kapsou M, Raftopoulos V, Soteriades ES. Knowledge, attitudes and beliefs of Cypriot nurses on the handling of antineoplastic agents. Eur J Oncol Nurs 2010; 14(4): 278-282. https://doi.org/10.1016/j.ejon.2010.01.025.

11. McLaws M, Momeni M, Oroei M, Danaei M, Askarian M, Palenik CJ. Obstacles to Cytotoxic Waste Management Perceived by Nurses in Shiraz, Iran. Journal NI 2015; 1(2): 9-14.

12. Manesh R, Panjali Z, Khani F, Habibi-Mohraz M, Borhani M. Knowledge and Attitude about Exposure to Cytotoxic Drugs in Oncology Nurses. Archives of Occupational Health 2019 10; 3(3): 371-379. https://doi.org/10.18502/aoh.v3i3.1280.

13. Momeni M, Danaei M, Askarian M. How do nurses manage their occupational exposure to cytotoxic drugs? A descriptive survey in chemotherapy settings, Shiraz, Iran. Int J Occup Environ Med 2013; 4(2): 102-106. https://pubmed.ncbi.nlm.nih.gov/23567536.

14. Elshamy K, El-Hadidi M, El-Roby M, Fouda M. Health hazards among oncology nurses exposed to chemotherapy drugs. Afr J Haematol $\begin{array}{lll}\text { Oncol 2010; } & \text { 1(3): }\end{array}$ https://theafjho.com/index.php/AJOHAO/article/view/20/31.

15. Worthington K. Chemotherapy on the Unit. Protecting the provider as well as the patient. Am J Nurs 2000; 100(4): 88. https://pubmed.ncbi.nlm.nih.gov/10776358.

16. Furlow BR. How to improve the safety of chemotherapy administration. Oncology Nurse Advisor 2010: 21-25. https://www.oncologynurseadvisor.com/wpcontent/uploads/sites/13/2019/01/ona_chemosafety0610 3396.pdf.

17. Bouraoui S, Brahem A, Tabka F, Mrizek N, Saad A, Elghezal H. Assessment of chromosomal aberrations, micronuclei and proliferation rate index in peripheral lymphocytes from Tunisian nurses handling cytotoxic drugs. Environ Toxicol Pharmacol 2011; 31(1): 250-257. https://doi.org/10.1016/i.etap.2010.11.004.

18. Suspiro A, Prista J. Biomarkers of occupational exposure do anticancer agents: a minireview. Toxicol Lett 2011; 207(1): 42-52. https://doi.org/10.1016/i.toxlet.2011.08.022.

19. Connor TH. Hazardous anticancer drugs in health care: environmental exposure assessment. Ann N Y Acad Sci 2006; 1076: 615-623. https://doi.org/10.1196/annals.1371.021. 
20. Ratner PA, Spinelli JJ, Beking K, Lorenzi M, Chow Y, Teschke K, et al. Cancer incidence and adverse pregnancy outcome in registered nurses potentially exposed to antineoplastic drugs. BMC Nurs 2010; 9: 15. https://doi.org/10.1186/1472-6955-9-15.

21. Constantinidis TC, Vagka E, Dallidou P, Basta $P$, Drakopoulos V, Kakolyris S, et al., Occupational health and safety of personnel handling chemotherapeutic agents in Greek hospitals. Eur J Cancer Care (Engl) 2011; 20(1): 123-131. https://doi.org/10.1111/j.13652354.2009.01150.x.

22. Martin S, Larson E. Chemotherapy-handling practices of outpatient and office-based oncology nurses. Oncol Nurs Forum 2003; 30(4): $575-$ 581. https://doi.org/10.1188/03.onf.575-581.

23. Kahangi LS, Babashahi M. Investigating Compliance With the Standard Principles of Using Personal Protective Equipment by Nurses Exposed to Chemotherapy Drugs. Journal of Clinical Nursing and Midwifery 2019; 7(4): 242-249. Persian. http://jcnm.skums.ac.ir/article-1-816en.html.

\section{Authors:}

Mohsen Momeni - MD, Assistant Professor, Department of Community Medicine, Neuroscience Research Center, Institute of Neuropharmacology, Kerman University of Medical Sciences, Kerman, Iran. https://orcid.org/0000-0002-9513-3046.

Mehrdad Askarian - MD, Professor, Department of Community Medicine, School of Medicine, Shiraz University of Medical Sciences, Shiraz,Iran; Health Behavior Science Research Center, Shiraz University of Medical Sciences, Shiraz, Iran. https://orcid.org/0000-0003-4163-7414.

Hossein Azad - MD, General Practitioner, HIV/STI Surveillance Research Center, WHO Collaborating Center for HIV Surveillance, Institute for Futures Studies in Health, Kerman University of Medical Sciences, Kerman, Iran. https://orcid.org/0000-0003-4721-7058.

Mina Danaei - MD, Assistant Professor, Department of Community Medicine, Social Determinants of Health Research Center, Institute for Futures Studies in Health, Kerman University of Medical Sciences, Kerman, Iran. https://orcid.org/0000-0002-6352-9599. 